\title{
INOVASI ALAT PENGATUR CATU DAYA TEGANGAN TINGGI PADA PESAWAT SINAR-X DIAGNOSTIK
}

\author{
SUJATNO, WIRANTO BUDI SANTOSO \\ PRPN-BATAN Kawasan Puspiptek Serpong
}

\begin{abstract}
Abstrak
INOVASI ALAT PENGATUR CATU DAYA TEGANGAN TINGGI PADA PESAWAT SINAR-X DIAGNOSTIK. Telah dilakukan inovasi alat pengatur catu daya tegangan tinggi pada pesawat sinar-x diagnostik. Inovasi dilakukan dengan menggunakan rangkaian elektronik sebagai alat pengatur catu daya tegangan tinggi. Pada umumnya pesawat sinar-x diagnostik menggunakan transformator atau autotransformator sebagai alat pengatur catu daya tegangan tinggi. Pesawat sinar- $\mathrm{x}$ diagnostik berdaya besar memerlukan transformator berdaya besar yang memiliki ukuran fisik yang besar. Karena itu kontrol boks untuk menempatkan transformator tersebut berukuran besar pula. Selain itu harga transformator berdaya besar cukup mahal dan sulit didapatkan di pasaran lokal. Pada inovasi ini, transformator digantikan dengan sebuah rangkaian elektronik. Komponen utama rangkaian elektronik ini adalah triac BTA-40. Sebagai alat pengatur, triac dikendalikan oleh resistor variabel yang dihubungkan dengan motor langkah (stepper motor). Pergerakan dari stepper motor mengubah nilai resistor. Nilai resistor menentukan besarnya tegangan pada gerbang (gate) triac. Selanjutnya triac akan membuka sesuai besarnya arus listrik yang mengalir ke gerbang. Ketika grabang terbuka, tegangan dan arus listrik akan mengalir dari katoda ke anoda pada triac. Besarnya tegangan dan arus listrik tergantung dari besarnya bukaan gerbang. Kemudian tegangan keluaran triac dialirkan ke catu daya tegangan tinggi pesawat sinar-x diagnostik. Dengan demikian besarnya tegangan tinggi pesawat sinar-x diagnostik dapat diatur oleh tegangan keluaran rangkaian elektronik. Dengan menggunakan rangkaian elektronik ini, ukuran fisik boks kontrol dari pesawat sinar-x diagnostik dan harga peralatan dapat dikurangi.
\end{abstract}

Kata kunci: tegangan tinggi, transformator, triac, pesawat sinar-X

\begin{abstract}
INNOVATION OF HIGH VOLTAGE SUPPLY ADJUSTMENT DEVICE ON DIAGNOSTIC X-RAY MACHINE. Innovation of high voltage supply adjustment device on diagnostic $\mathrm{x}$-ray machine has been carried out. The innovation is conducted by utilizing an electronic circuit as a high voltage adjustment device. Usually a diagnostic x-ray machine utilizes a transformer or an auto-transformer as a high voltage supply adjustment device. A high power diagnostic x-ray machine needs a high power transformer which has big physical dimension. Therefore a box control where the transformer is located has to have big physical dimension. Besides, the price of the transformer is expensive and hardly found in local markets. In this innovation, the transformer is replaced by an electronic circuit. The main component of the electronic circuit is Triac BTA-40. As adjustment device, the triac is controlled
\end{abstract}


by a variable resistor which is coupled by a stepper motor. A step movement of stepper motor varies a value of resistor. The resistor value determines the triac gate voltage. Furthermore the triac will open according to the value of electrical current flowing to the gate. When the gate is open, electrical voltage and current will flow from cathode to anode of the triac. The value of these electrical voltage and current depend on gate open condition. Then this triac output voltage is feeded to diagnostic $\mathrm{x}$-ray machine high voltage supply. Therefore the high voltage value of diagnostic $\mathrm{x}$ ray machine is adjusted by the output voltage of the electronic circuit. By using this electronic circuit, the physical dimension of diagnostic x-ray machine box control and the price of the equipment can be reduced.

Keywords: high voltage, transformer, triac, x-ray machine

\section{PENDAHULUAN}

Catu daya tegangan tinggi (High Voltage $-H V$ ) pada pesawat sinar-X diagnostik berfungsi untuk mencatu tegangan kerja pada tabung sinar-X. Besarnya tegangan ini mempengaruhi intensitas sinar-X yang dihasilkan oleh tabung. Pada pesawat sinar-X diagnostik konvensional pengaturan besarnya tegangan tinggi ini dilakukan dengan menggunakan transformator atau autotransformator yang mendapat masukan dari sumber listrik PLN. Sayangnya transformator atau auto-transformator yang mempunyai daya besar hingga sanggup untuk mencatu tegangan yang diperlukan sangat sulit dicari di pasaran lokal. Selain itu dimensi fisik dari transformator tersebut cukup besar sehingga boks kontrol untuk menempatkan transformator tersebut juga menjadi besar. Pada inovasi ini, pengaturan catu daya tegangan tinggi pesawat sinar-X diagnostik dilakukan tidak dengan menggunakan transformator melainkan dengan menggunakan rangkaian elektronik. Komponen utama rangkaian elektronik pengatur catu daya tegangan tinggi pesawat sinar-X diagnostik adalah triac (triode alternating current). Komponen ini berdimensi kecil namun mempunyai daya besar. Selain itu harga komponen ini lebih murah dan mudah didapatkan di pasaran lokal.

\section{TEORI}

Pengaturan catu daya tegangan tinggi pada pesawat sinar- $\mathrm{X}$ diagnostik konvensional dilakukan dengan mengunakan auto-transformer. Tegangan masukan auto-transformer berasal dari catu PLN. Blok diagram sistem tegangan tinggi pada pesawat sinar- $\mathrm{X}$ diagnostik konvensional dapat dilihat pada Gambar 1. 


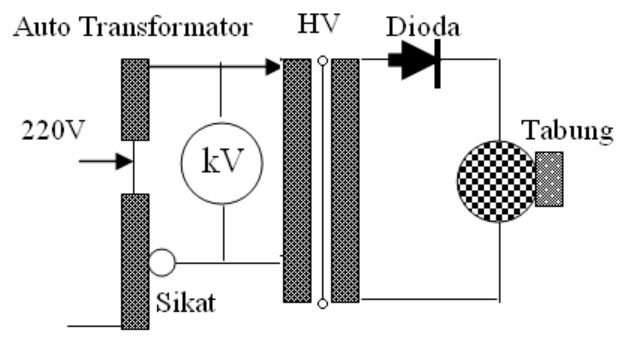

Gambar 1. Blok Diagram Sistem hv Pesawat sinar-X Diagnostik ${ }^{[1]}$.

Pada inovasi ini pengaturan catu daya tegangan tinggi dilakukan tidak menggunakan auto-transformator melainkan dengan menggunakan rangkaian elektronik. Komponen utama rangkaian elektronik ini adalah triac (triode alternating current).

Triac adalah alat yang dalam operasinya sangat mirip dengan SCR (Silicon Controlled Rectifier) $^{[2]}$. Pada SCR, jika dihubungkan ke dalam rangkaian ac maka tegangan output disearahkan menjadi arus searah. Namun pada triac, arus keluaran tetap merupakan arus bolak-balik. Triac dirancang untuk menghantarkan arus pada kedua belahan bentuk gelombang. Triac mempunyai tiga terminal, yaitu: terminal utama MT2 dan MT1 serta gerbang G.

Proses pemicuan (trigerring) akan dibahas dengan mengacu pada rangkaian yang terdapat pada Gambar 2. Kapasitor $\mathrm{C}$ akan mengisi muatannya melewati R1 dan R2 setiap setengah perioda.

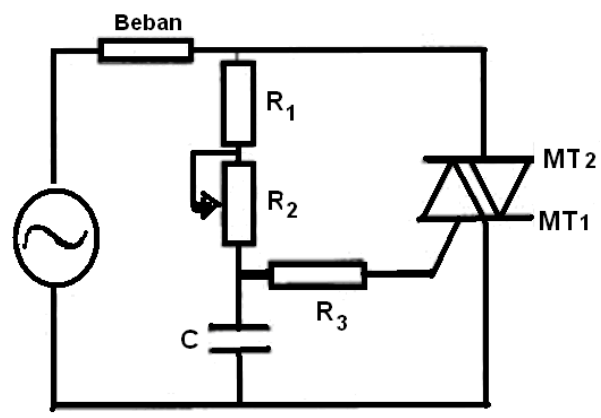

Gambar 2. Rangkaian Pemicu Triac ${ }^{[1]}$

Selama setengah perioda positip, MT2 akan akan lebih positip dari MT1, sehingga pelat atas kapasitor akan bermuatan positip. Jika tegangan pada kapasitor muncul hingga mencapai harga yang mencukupi untuk pemenuhan arus gate, maka Triac akan ON. Kecepatan pengisian kapasitor diatur oleh 
potensiometer R2, dimana jika hambatannya besar, maka pengisiannya akan lambat sehingga terjadi penundaan penyalaan. Jika nilai R2 kecil, maka pengisian kapasitor akan lebih cepat dan arus yang mengalir ke beban akan tinggi.

Proses pemicuan dapat juga dilakukan dengan menggunakan diac (dioda alternating current). Diac mempunyai dua buah elektroda atau terminal dan dapat menghantar dari kedua arah oleh karenanya diac dianggap sebagai homo atau non-polar. Diac tersusun dari empat lapis semikonduktor seperti dioda lapis empat.

Diac mempunyai impedansi yang tinggi dalam dua arah. Untuk mencapai titik konduknya diperlukan tegangan antara 28 sampai 36 volt. Jika tegangan diberikan pada diac menyamai atau melebihi tegangan konduknya, maka salah satu saklar akan menutup, demikian sebaliknya untuk kondisi yang sama salah satu saklarnya juga akan menutup. Rangkaian pemicauan dengan memanfaatkan diac dapat dilihat pada Gambar 3.

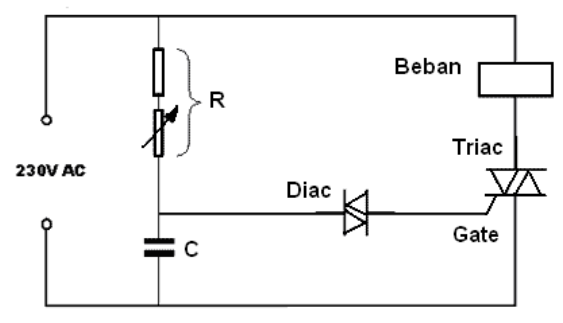

Gambar 3. Rangkaian Pemicu Triac ${ }^{[3]}$

\section{TATA KERJA}

Bahan utama dari penelitian ini menggunakan komponen aktip Triac BTA 40 yang menggunakan pemicu diac 1N5758 dan didukung dengan komponen pasip serta motor stepper. Peralatan yang dipakai osciloskop, pulsa generator dan beban (lampu, motor)

\section{Metode}

Pada pesawat sinar-X konvensional pengatur catu tegangan ke HV menggunakan auto transformator, kemudian sikat pengatur digerakan secara manual atau otomatis dengan menggunakan motor. Gambar blok diagram sistem pengatur konvensional seperti terlihat pada Gambar 1. Konstruksi auto transformator dan motor penggerak sikat pengatur seperti terlihat pada Gambar 4. 


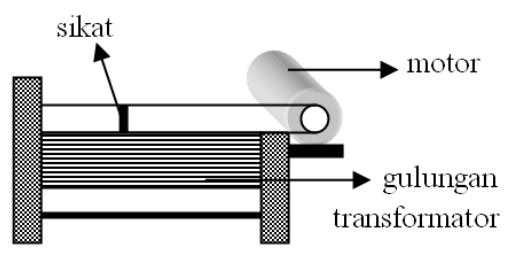

Gambar 4. Konstruksi Auto Transformator dan Motor Penggerak Sikat

Pada saat pesawat sinar-X dioperasikan maka sumber tegangan dari PLN masuk ke auto transfomator, kemudian keluaran dari auto transfomator diseting sesuai dengan tegangan tinggi yang dibutuhkan. Tegangan di auto transformator masih berupa teganagan rendah antara $0-240 \mathrm{~V}$, selanjutnya masuk ke HV dinaikkan menjadi kilo Volt. Tegangan kerja untuk tabung pesawat sinar-X diagnostik dengan daya sedang antara $50 \mathrm{kV}-100 \mathrm{kV}$. Jadi fungsi alat pengatur adalah untuk mengatur catu tegangan ke sistem HV. Jika alat pengatur ini menggunakan trafo atau auto-transformator dimensinya cukup besar, karena yang harus dicatu berdaya tinggi. Selain itu harganya cukup mahal dan sulit dicari dipasaran lokal, sehingga tidak efisien dan tidak ekonomis. Dengan kemajuan teknologi di bidang elektronika, maka memungkinkan dibuat alat pengatur HV dengan rangkaian elektronik. Tinggal bagaimana rangkaian elektronik tersebut dikemas sehingga dapat berfungsi dan handal. Untuk itu telah dibuat alat pengatur $\mathrm{HV}$ dengan menggunakan rangkaian elektronik dimana kendali utamanya digunakan triac yang mampu untuk daya tinggi. Dengan mengatur gerbang (gate) triac maka tegangan keluarannya dapat dikendalikan. Tegangan yang telah teregulasir dari keluaran triac kemudian digunakan sebagai catu tegangan ke trafo tegangan tinggi. Alat pengatur dengan menggunakan triac seperti terlihat pada Gambar 5.

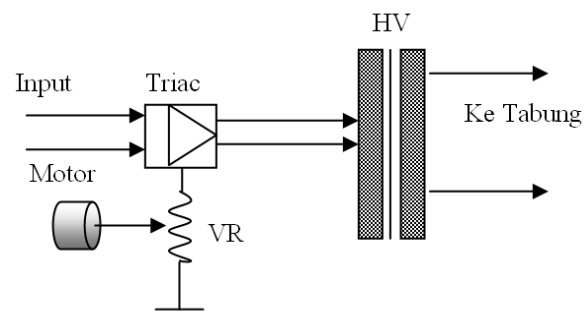

Gambar 5. Blok Diagram Alat Pengatur HV ${ }^{[3]}$ 


\section{HASIL DAN PEMBAHASAN}

Rangkaian pengatur catu daya tegangan tinggi yang dibuat dapat dilihat pada Gambar 6.

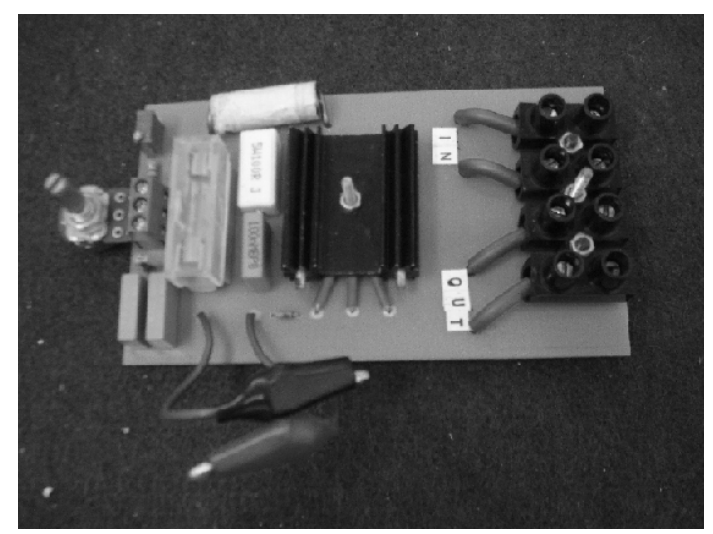

Gambar 6. Alat Pengatur hv

Tabel 1. Hasil Pengujian Rangkaian dengan Beban

\begin{tabular}{ccccc}
\hline No & $\begin{array}{c}\text { VR } \\
\text { (ohm) }\end{array}$ & $\begin{array}{c}\text { Arus (Ig) } \\
\text { (mA) }\end{array}$ & $\begin{array}{c}\text { Tegangan } \\
\text { Vo(Volt) }\end{array}$ & $\begin{array}{c}\text { Beban } \\
\text { (Watt) }\end{array}$ \\
\hline 1. & $459 \mathrm{~K}$ & 0,1 & 50 & 40 \\
2. & $350 \mathrm{~K}$ & 0,2 & 90 & \\
3. & $241 \mathrm{~K}$ & 0,35 & 130 & \\
4. & $111 \mathrm{~K}$ & 0,8 & 175 & \\
5. & 1,3 & 1,4 & 203 & \\
6. & $451 \mathrm{~K}$ & 0,1 & 40 & 100 \\
7. & $341 \mathrm{~K}$ & 0,2 & 85 & \\
8. & $236 \mathrm{~K}$ & 0,3 & 125 & \\
9. & $127 \mathrm{~K}$ & 0,7 & 167 & \\
10. & 32,3 & 1,4 & 204 & \\
11. & $433 \mathrm{~K}$ & 0,1 & 45 & 140 \\
12. & $337 \mathrm{~K}$ & 0,2 & 85 & \\
13. & $240 \mathrm{~K}$ & 0,3 & 125 & \\
14. & $130 \mathrm{~K}$ & 0,6 & 165 & \\
15. & 1,2 & 1,2 & 209,4 & \\
16. & $174 \mathrm{~K}$ & 0,15 & 32 & 400 \\
17. & $153 \mathrm{~K}$ & 0,175 & 45 & \\
18. & $125 \mathrm{~K}$ & 0,2 & 55 & \\
19 & $91 \mathrm{~K}$ & 0,3 & 65 & \\
20. & $53 \mathrm{~K}$ & 0,42 & 78 & \\
21. & 1,3 & 2,5 & 98 & \\
\hline
\end{tabular}

Dari hasil pengujian yang terlihat pada Tabel 1, jika gate triac dipicu dengan arus kecil maka tegangan yang dapat lewat juga rendah. Apabila gate dipicu dengan arus yang besar maka tegangan yang lewat dapat tinggi. Untuk 
mengatur arus gate digunakan potensio (VR) yang direncanakan digerakan dengan motor stepper, sehingga dapat beroperasi secara otomatis. Pengaturan catu tegangan ke HV dilakukan melalui sisi primer dari trafo HV yang merupakan tegangan rendah. Hasil setting keluaran tegangan dari triac disalurkan ke lilitan primer trafo $\mathrm{HV}$, sehingga lilitan sekundernya menghasilkan tegangan tinggi yang sebanding dengan setting tersebut. Selanjutnya hasil keluaran HV digunakan sebagai catu tegangan kerja pada tabung pesawat sinar-X diagnostik ${ }^{[1]}$.

Jenis triac atau SCR yang digunakan adalah yang mempunyai daya tinggi, karena beban yang harus dipikul cukup besar. Pada pengujian ini digunakan triac type RD91 yang termasuk kelompok BTA40. Triac tersebut mempunyai kemampuan yang cukup tinggi yaitu arus mampu sampai $40 \mathrm{~A}$, temperatur $80^{\circ} \mathrm{C}$ dan tegangan $600 \mathrm{Volt}^{[1]}$. Gambar blok diagram hasil disain alat pengatur secara lengkap seperti terlihat pada Gambar 7.

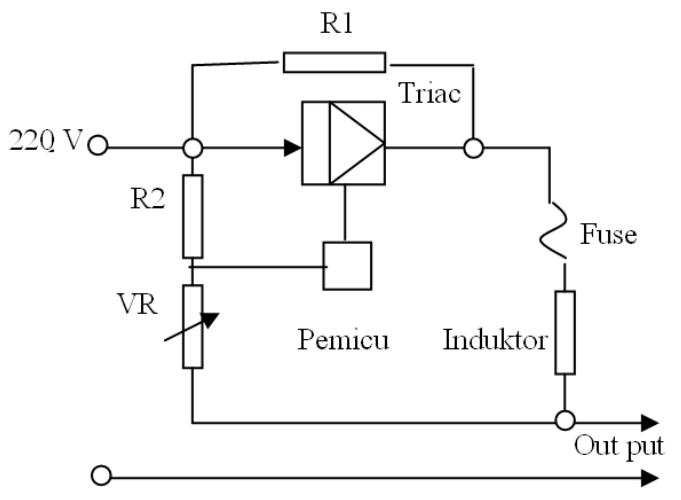

Gambar 7. Blok Diagram Alat Pengatur hv

\section{KESIMPULAN}

Dari hasil pengujian dapat disimpulkan sebagai berikut :

1. Jika gate triac dipicu dengan arus yang bervariasi, maka keluarannya (Vo) juga akan bervariasi.

2. Besar kecil keluaran triac tergantung dari besar arus pemicu.

3. Pengaturan arus pemicu tergantung dari setting tegangan geser (VR).

\section{UCAPAN TERIMA KASIH}

Penulis mengucapkan terima kasih pada Kepala PRPN yang telah memberikan izin untuk menggunakan fasilitas serta peralatan untuk 
melakukan kegiatan ini. Tak lupa penulis juga mengucapkan terima kasih kepada pihak-pihak yang telah membantu pelaksanaan kegiatan ini, terutama rekan-rekan di Bidang Instrumentasi Kesehatan dan Keselamatan PRPN, dan saudara Eril dalam pengambilan data percobaan.

\section{DAFTAR PUSTAKA}

1. ANONIM, Manual Operating X-Ray, Dong Wang, China

2. FRANK.D.PETRUZELLA, 1986, Elektronika Industri, Andi, Jogjakarta.

3. RALPH J SMITH, 1992, Rangkaian Piranti dan Sistem, Erlangga, Jakarta 